\title{
Macular edema in siliconized eyes
}

\author{
Abdullah Kaya \\ Yakup Aksoy ${ }^{2}$ \\ Yıldıray Yildirim ${ }^{3}$ \\ Murat Sonmez \\ 'Department of Ophthalmology, \\ Anıttepe Military Dispensary, \\ Ankara, Turkey; ${ }^{2}$ Department of \\ Ophthalmology, Girne Military \\ Hospital, Girne, Cyprus; ${ }^{3}$ Department \\ of Ophthalmology, GATA Haydarpasa \\ Training Hospital, Istanbul, Turkey
}

This article was published in the following Dove Press journal:

Clinical Ophthalmology

3 May 2016

Number of times this article has been viewed

\section{Dear editor}

We read with great interest the article titled "Value of optical coherence tomography in the detection of macular pathology before the removal of silicone oil" by Rashad et al. ${ }^{1}$ The authors have evaluated the optical coherence tomography (OCT) findings before the removal of silicone oil ( $\mathrm{SiO})$. We congratulate the authors for this wellorganized study and would like to contribute to their findings.

OCT is a revolutionary investigation in ophthalmology. ${ }^{2}$ It provides an opportunity to visualize the histological structure of the retina. $\mathrm{SiO}$ plays a very important role in ophthalmic surgery and is used as a tamponade agent in a lot of vitreoretinal surgeries. ${ }^{3}$ OCT findings of siliconized eyes may provide us with new insights about the proper timing of removal of $\mathrm{SiO}$ and deciding on additional treatments. Thus, findings discussed in this study are very important.

One of the significant findings of this study is the high percentage of macular edema (ME) in siliconized eyes. Being an important pathology that impairs visual acuity, we think the high percentage of ME in this study should be well analyzed. We wonder if $\mathrm{ME}$ was present before the injection of $\mathrm{SiO}$ or developed under $\mathrm{SiO}$. The incidence of ME was found to be high, especially in diabetic patients (58.3\%). Diabetic patients suffer from microcirculation problem. ${ }^{4}$ Existence of $\mathrm{SiO}$ may decrease oxygenation of the retina and increase the risk of developing ME. Thus, follow-up with OCT is especially important in diabetic patients.

Treatment of ME in siliconized eyes is also an important issue. We wonder which pharmacotherapy the authors used. Intravitreal anti-vascular endothelial growth factor, the most efficient drug for ME, is useless in this situation. While topical nonsteroidals are efficient in treating postoperative ME, we do not know if they would be efficient in siliconized eyes. Subtenon steroid injection may be an efficient treatment. Based on OCT findings, early removal of silicone and intravitreal anti-vascular endothelial growth factor may be applied.

\section{Disclosure}

The authors report no conflicts of interest in this communication.

\section{References}

1. Rashad MA, Mohamed AA, Ahmed AI. Value of optical coherence tomography in the detection of macular pathology before the removal of silicone oil. Clin Ophthalmol. 2016;10:121-135.

2. Huang D, Swanson EA, Lin CP, et al. Optical coherence tomography. Science. 1991;254:1178-1181.

3. Cibis PA, Becker B, Okun E, Cowan S. The use of liquid silicone in retinal detachment surgery. Arch Ophthalmol. 1962;681:590-599.

4. Ichiyama Y, Sawada O, Mori T, Fujikawa M, Kawamura H, Ohji M. The effectiveness of vitrectomy for diffuse diabetic macular edema may depend on its preoperative optical coherence tomography pattern Graefes Arch Clin Exp Ophthalmol. Epub 2016 Jan 18. 


\section{Authors' reply}

Mohammad Ahmad Rashad

Ahmed Abdel Aliem Mohamed

Asmaa Ismail Ahmed

Department of Ophthalmology, Faculty of Medicine, Ain Shams University, Cairo, Egypt

Correspondence: Mohammad Ahmad Rashad

Department of Ophthalmology, Faculty of Medicine, Ain Shams University, 79 Othman Buildings, Ali Amen Street, Nasr City, Cairo, Egypt

Tel +20 I2 23463327

Email mohammadahmadrashadeyelaser@gmail.com

\section{Dear editor}

Thank you for the opportunity to respond to Dr Kaya et al's letter titled "Macular edema in siliconized eyes". We read their comments with great concern. We appreciate their effective contribution. We thank them for their illustrative questions about our study. The main concern of our study was to report the superiority of optical coherence tomography (OCT) in silicone oil ( $\mathrm{SiO}$ )-filled eyes over clinical examination. However, this letter will give us a chance to illustrate more facts and details about our results.

We have reported macular edema in $27.5 \%$ of all eyes. It was the second most common pathological change after epiretinal membrane (41.2\%) under SiO. Eyes with clinically normal fundus under $\mathrm{SiO}$ were 22 (43\% of all eyes). Of these, five eyes $(22 \%)$ had macular edema discovered by OCT. We have described macular edema as being of two types.

The first entity was diabetic macular edema (DME), which was found in $58.3 \%$ of eyes with preoperative diagnosis of proliferative diabetic retinopathy. All of these eyes had traction retinal detachment involving the macula before pars plana vitrectomy and $\mathrm{SiO}$ injection, proven by OCT (Figure 1). Any macular edema before injection of $\mathrm{SiO}$ was of traction type. This type of traction DME has been resolved by performing vitrectomy. Lewis et $\mathrm{al}^{1}$ described vitrectomy with posterior vitreous separation in ten eyes with DME and coined the term taut posterior hyaloid before the use of OCT. They described resolution of DME in eight eyes and reduction in two. Gandorfer et $\mathrm{al}^{2}$ described resolution of macular edema in 60 of 61 eyes with vitrectomy and removal of epimacular tissue that was not dependent on removal of all membranes. They used electron microscopy. We consider that DME in our study was a new development in the presence of $\mathrm{SiO}$.

A mechanism mentioned by Dr Kaya, which is decreased oxygenation of the macula causing DME, is considerable especially when we report our type of treatment and response to it.

Regarding treatment, we did not use the pharmacotherapy before SiO removal. Actually, we have performed OCT

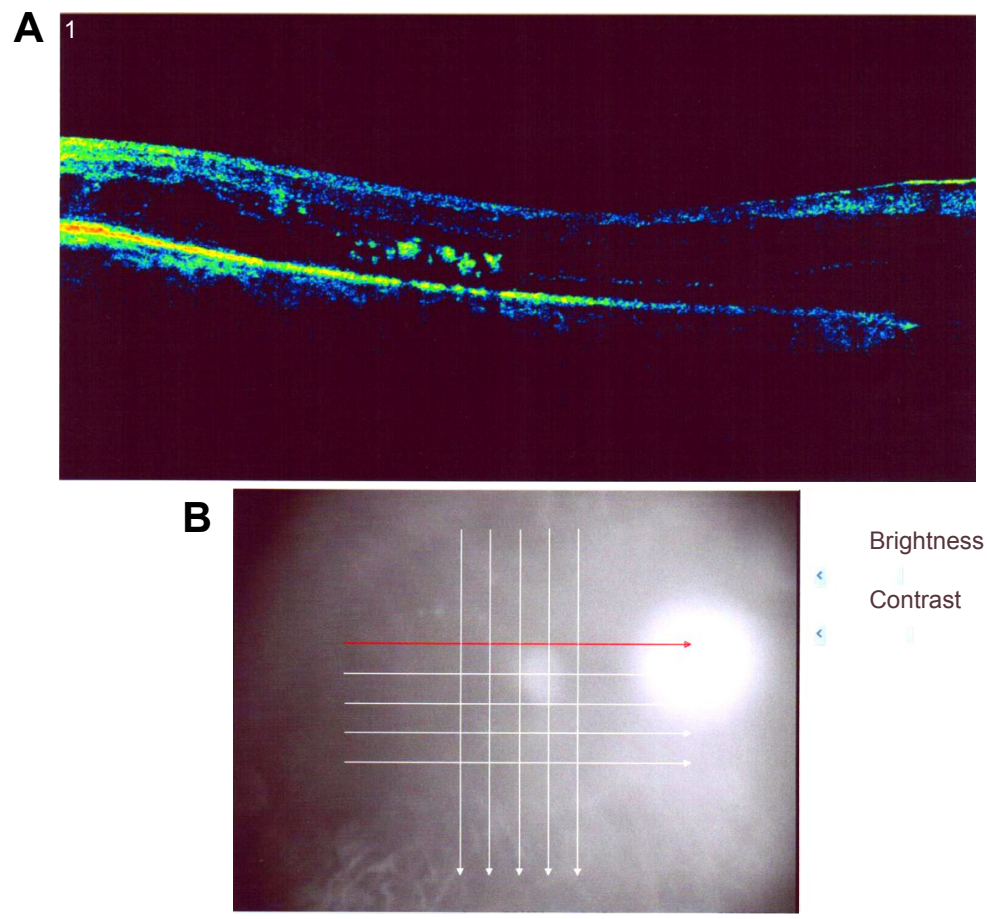

Figure I Case of the proliferative diabetic retinopathy group before silicone oil injection with traction retinal detachment involving macula shown in selected cut in the top (A) and raster cuts in the bottom (B).

Notes: The red arrow indicates the cut section shown in $\mathbf{A}$. 
just before $\mathrm{SiO}$ removal to detect any pathological change that would need to be treated during $\mathrm{SiO}$ removal either surgically or pharmacologically. The pharmacotherapy we used in DME was intravitreal anti-vascular endothelial growth factor (VEGF) at the time of SiO removal. We have observed that DME did not recur in five of seven eyes (70\%), and that it recurred in two eyes only once and responded to anti-VEGF reinjection. Response to anti-VEGF injection proves the ischemic origin of DME. Response to a single injection in most eyes proves that it was induced in part by the presence of $\mathrm{SiO}$.

The other entity of macular edema we described was cystoid macular edema (CME). It was present in 33\% of proliferative vitreoretinopathy eyes and $25 \%$ of uveitic eyes. This distribution may be in favor of explanation of mechanism of toxicity to $\mathrm{SiO}$ rather than inflammatory mediators.

In their case report, Haider et $\mathrm{al}^{3}$ described CME with the use of $\mathrm{SiO}$ after vitrectomy that resolved spontaneously 1 month after the removal of SiO. They explained the mechanism to be either inflammatory or traction.

In the case of CME, we used pharmacotherapy at the time of $\mathrm{SiO}$ removal. It was in the form of posterior subtenon triamcinolone. It was used once in five eyes, was repeated twice in one eye, and was repeated four times in one eye with the development of glaucoma that responded to medical treatment. We tend to explain $\mathrm{CME}$ to be due to toxicity of $\mathrm{SiO}$ because of response to a single injection in $70 \%$ of eyes. Using gas chromatography, Nakamura et $\mathrm{al}^{4}$ described decreased concentration of low-molecular-weight components in $\mathrm{SiO}$ for up to 2 years after injection. These impurities probably diffused from the oil into the tissues, resulting in toxicity.

We agree with Dr Kaya about the high percentage of macular edema in siliconized eyes in our study and that follow-up with OCT should be recommended, especially in diabetic patients. We think that early removal of $\mathrm{SiO}$ should be considered when macular edema is detected by OCT and this should be weighed against the possibility of recurrence with premature $\mathrm{SiO}$ removal. In diabetic SiO-filled eyes, intravitreal anti-VEGF should be ready to be used if DME is detected by routine OCT before $\mathrm{SiO}$ removal.

\section{Disclosure}

The authors report no conflicts of interest in this communication.

\section{References}

1. Lewis H, Abrams GW, Blumenkranz MS, Campo RV. Vitrectomy for diabetic macular traction and edema associated with posterior hyaloidal traction. Ophthalmology. 1992;99(5):753-759.

2. Gandorfer A, Rohleder M, Grosselfinger S, Haritoglou C, Ulbig M, Kampik A. Epiretinal pathology of diffuse diabetic macular edema associated with vitreomacular traction. Am J Ophthalmol. 2005;139(4): 638-652.

3. Haider A, Bababeygy SR, Lu SY. Cystoid macular edema following silicone oil tamponade for retinal detachment surgery. J Clin Ophthalmol. 2015;2(1):1042

4. Nakamura K, Refojo MF, Crabtree DV, Pastor J, Leong FL. Ocular toxicity of low-molecular-weight components of silicone and fluorosilicone oils. Invest Ophthalmol Vis Sci. 1991;32(12):3007-3020.

Dove Medical Press encourages responsible, free and frank academic debate. The content of the Clinical Ophthalmology 'letters to the editor' section does not necessarily represent the views of Dove Medical Press, its officers, agents, employees, related entities or the Clinical Ophthalmology editors. While all reasonable steps have been taken to confirm the content of each letter, Dove Medical Press accepts no liability in respect of the content of any letter, nor is it responsible for the content and accuracy of any letter to the editor.

\section{Publish your work in this journal}

Clinical Ophthalmology is an international, peer-reviewed journal covering all subspecialties within ophthalmology. Key topics include: Optometry; Visual science; Pharmacology and drug therapy in eye diseases; Basic Sciences; Primary and Secondary eye care; Patient Safety and Quality of Care Improvements. This journal is indexed on

Submit your manuscript here: http://www.dovepress.com/clinical-ophthalmology-journal
PubMed Central and CAS, and is the official journal of The Society of Clinical Ophthalmology (SCO). The manuscript management system is completely online and includes a very quick and fair peer-review system, which is all easy to use. Visit http://www.dovepress.com/ testimonials.php to read real quotes from published authors. 